\title{
The Selected Factors Related with Mental Health Power of Nursing Undergraduate Students, Srimahasarakham Nursing College, Praboromarajhanok Institute of Thailand
}

\author{
Kuantean Wongchantra ${ }^{1}$, Naovarat Singsanun ${ }^{1}$, Jarunee Intharit ${ }^{1} \&$ Prayoon Wongchantra $^{2}$ \\ ${ }^{1}$ Srimahasarakham Nursing College, Faculty of Nursing, Praboromarajhanok Institute, Maha Sarakham, Thailand \\ ${ }^{2}$ Faculty of Environment and Resource Studies, Mahasarakham University, Maha Sarakham, Thailand \\ Correspondence: Prayoon Wongchantra, Faculty of Environment and Resource Studies, Mahasarakham University, \\ Maha Sarakham, Thailand.
}

Received: May 6, 2021

Accepted: May 16, 2021

Online Published: May 18, 2021

doi:10.5430/ijhe.v10n5p183

URL: https://doi.org/10.5430/ijhe.v10n5p183

\begin{abstract}
The purposes of this research were to study the level of mental health power and selected factors related to mental health power of nursing undergraduate students, Srimahamarakham Nursing College. The sample consisted of 91 first-year nursing undergraduate students at Srimahasarakham Nursing College, Faculty of Nursing, Praboromarajhanok Institute who were selected by purposive sampling. The research tool was the mental health power assessment questionnaire. The statistics used for data analysis were frequency, percentage, mean, standard deviation and the spearman's correlation coefficient. The results showed that the mean of overall mental health power was lower than the criteria $\left(\mathrm{x}^{-}=57.64\right)$. When considering mental health power on each aspect, it was found that emotional stability $\mathrm{x}^{-}=28.98$, encouragement $\mathrm{x}^{-}=13.81$ and problem management $\mathrm{x}^{-}=14.84$ which is below the threshold level on all aspects. And factors that had a positive correlation with the mental health power of nursing undergraduate students statistical significance $(\mathrm{p}<.05)$. There was also a moderate correlation $(\mathrm{r}=.04)$ were associated homeland low level $(\mathrm{r}=.01)$ and monthly income had a moderate relationship $(\mathrm{r}=.03)$. The factors that did not relate with the mental health power of nursing undergraduate students were gender $(\mathrm{r}=.10)$ and the order of siblings or their children $(\mathrm{r}=.09)$.
\end{abstract}

Keywords: mental health power, selected factors, emotional stability, morale, problem management

\section{Introduction}

Currently, the management of nursing education consists of theoretical and practical studies. This may cause the nursing undergraduate students to have conflicts and frustrations over the teaching and learning models provided by educational institutions which is mainly due to the individual condition this may happen, especially the practice of nursing students. If the student is reprimanded being scolded or not accepted by health personnel in the ward or even the patients cared by nursing students can cause stress to students (Atsawini Manakankham et al., 2004). The factors causing stress in nursing students to practice at the ward consisted of the personal characteristics of the supervisory teacher, characteristics of practice and patient care, characteristics of staff and personnel in the ward, personal characteristics of students, characteristics of teacher supervision (Saymai Tumwichit et al., 2009). As mentioned above, those involved in nursing teaching and learning must pay more attention to such issues in order to reduce any problems that may happen to nursing students. However, if the instructor has prepared appropriate teaching and learning arrangements on the part of nursing students themselves, they are equipped with a high level of self-learning, group work and are ready to solve any problems well in the future (Areewan Klunklin et al., 2008).

However, the social expectations of graduating from high-risk nurses work under stressful circumstances life and death expectation of patients and relatives nurses must be physically strong along with mental strength. During the study, in addition to giving knowledge in various fields in order to develop competence in nursing practice, it is imperative to develop a strong psychological integrity simultaneously. In order to graduate out as a graduate nurse who is both healthy and healthy, have a high competence in nursing practice and strong mental health to continue to be a complete healthcare provider. Which mental health according to the World Health Organization (WHO) definition, it refers to the state of a person with good health, well-being, awareness of their own potential being able to deal with stress in working life effectively and efficiently, including being involved in the community and society. A 
person's mental health is therefore an important part of their well being. It consists of physical, mental and social health that promotes the ability to sustain and fulfill life, having a relationship with other people, study, work, and recreational activities and choosing or making decisions. Everyday life encompasses a variety of environments, personalities, emotions, society, regulations and location, all of which affect a person's mental health condition causing stress deviated mental health or even mental and psychiatric problems (Rattanaphon Phanphot et al., 2016).

For nursing undergraduate students are at risk of developing mental health problems due to stress because there are circumstances that will cause stress in all classes of nursing. First-year nursing undergraduate students have to face the transition from the basic education system to be the higher education system. There are new environment, new friends, new culture, living from home to dormitory so they underwent a drastic lifestyle change and it is often the cause of stress problems that often show signs of physical illness. While second-year nursing undergraduate students have experience a change in their study of different subjects. It is the transition from the general basic subject to the start of the new vocational-related subject, which is a new subject that has never been seen before. It will find that students who are unsure of their true love for nursing will begin to find that the nursing profession and often found resignation of students. It will find that students who are unsure of their true love for nursing will begin to find that. The nursing profession and often found resignation of students. Third year nursing students had stress factors and mental health problems because students will have to go through more intensive theory and practice sessions on many subjects. Especially in practice in Srimahasarakham Nursing College, Faculty of Nursing, Praboromarajhanok Institute, they have to practice practical training, in many provinces, many levels of the hospital, both physical and mental which in the third year they will find the factors of stress, practical subjects and fatigue, including adapting to the discipline and professional culture appropriately. For the fourth year nursing undergraduate students are stress factors from the expectations of the family institution with a student and sometimes it's the problems and stress that have accumulated over the years that have not been properly addressed which when found is often so severe that it is a mental health problem.

As mentioned above, it is found that nursing undergraduate students have risk factors that can cause stress and mental health problems in every year. Therefore, without proper stress relief and coping, there may be more serious mental health problems until unable to complete the course. It also causes physical and mental harm, resulting in the loss of education, economy and society. Since nursing undergraduate students of Praboromarajhanok Institute are students with scholarships from all agencies and from statistics of illness and requesting to receive a consultation in health, it was found that there are more students seeking advice from teachers. In addition, it was found that some students had illnesses that expressed sadness, self-harm or psychological illnesses that expressed uncontrollable physical conditions. And some have to be quit a mental illness that cannot be cured in a short time.

So, the researcher is interested in investigating, the selected factor related to the mental health power of all nursing undergraduate students, practitioners and deal with mental health problems to be comprehensive in line with students' problems. To provide all students with comprehensive mental health care suitable for their individual problems. This is in line with the policy of Srimahasarakham Nursing College, which is a higher education institute, producing nursing undergraduates students to meet professional standards and must have intellectual excellence, have a good attitude, adhere to virtue continuous self-development and learning for a happy life in society. This research has the objective to study the level of mental health power and selected factors related to mental health power of nursing undergraduate students, Srimahasarakham Nursing College, Faculty of Nursing, Praboromarajhanok Institute of Thailand.

\section{Method}

\subsection{Population and Sample}

The population used in this research were 416 nursing undergraduate students, Srimahasarakham Nursing College, Faculty of Nursing, Praboromarajhanok Institute of Thailand. Details are as follows: 
Table 1. Samples classified by grade level.

\begin{tabular}{lccc}
\multicolumn{1}{c}{ Academic Year } & $\begin{array}{c}\text { Gender (Frequency / person) } \\
\text { Male }\end{array}$ & Female & Total \\
\hline $\begin{array}{l}\text { 1st year nursing undergraduate } \\
\text { students }\end{array}$ & 3 & 88 & 91 \\
$\begin{array}{l}\text { 2nd year nursing undergraduate } \\
\text { students }\end{array}$ & 8 & 92 & 100 \\
$\begin{array}{l}\text { 3rd year nursing undergraduate } \\
\text { students }\end{array}$ & 14 & 173 & 187 \\
$\begin{array}{l}\text { 4th year nursing undergraduate } \\
\text { students }\end{array}$ & 3 & 35 & 38 \\
& $\mathbf{2 8}$ & $\mathbf{3 8 8}$ & $\mathbf{4 1 6}$
\end{tabular}

The sample used in this research were 91 first-year nursing undergraduate students, Srimahasarakham Nursing College, Faculty of Nursing, Praboromarajhanok Institute of Thailand, which was obtained by purposive sampling.

\subsection{Variables}

1) The independent variables were age, gender, hometown, order of siblings/children who and monthly income.

2) The dependent variable were mental health power of nursing undergraduate students consists of three aspects: emotional stability, morale and problem management.

\subsection{Construction and Quality of Tools}

1) Study of basic information; study of content, background information and related research papers to obtain preliminary information before creating a mental health assessment.

2) Build a research tool; define the objectives and scope the content of the tools to be associated with the objectives. All data studied were used to compile the knowledge and analyzed the content framework for preparing the mental health assessment. This is a person's ability to adjust and recover after experiencing a crisis or difficult situation. It is one quality that helps a person overcome obstacles and lead a happy life. The mental health power assessment or RQ. It is a tool to assess a person's ability in three areas: emotional stability, morale, and problem management. If assessed and found that any component is below the threshold, can develop people in that area to give more, which is defined as the question of the assessment section, divided into 4 levels, total 20 items, with the following scoring criteria:

Mental health power level; 1means untrue, 2 means true sometimes, 3 means quite true and 4 means very true

The conversion of score values is as follows:

Table 2. RQ scoring criteria

\begin{tabular}{lccc}
\hline \multicolumn{1}{c}{ Elements of RQ } & $\begin{array}{c}\text { Below the } \\
\text { threshold }\end{array}$ & Normal & $\begin{array}{c}\text { Above the } \\
\text { threshold }\end{array}$ \\
\hline Emotional stability (1-10) & $<27$ & $27-34$ & $>34$ \\
Morale (11-15) & $<14$ & $14-19$ & $>19$ \\
Problem management (16-20) & $<13$ & $13-18$ & $>18$ \\
\multicolumn{1}{c}{ Total (Score 80 points) } & $<\mathbf{5 5}$ & $\mathbf{5 5 - 6 9}$ & $>\mathbf{6 9}$
\end{tabular}

Emotional stability means having mind that is not easily sensitive, be able to tolerate pressure and have a way to deal with emotions.

Morale means being determined and not giving up.

Problem management means having positive outlook on problems and having solutions to them.

RQ evaluation results:

Emotional stability (1-10), get 27-34 points, your assessment result is normal.

Morale (Clause 11-15), get 14-19 points, your assessment result is normal.

Problem management (16-20), get 13-18 points, your assessment result is normal 
Total scores 55-69, assessment is normal.

3) Take the mental health power assessment form 5 experts to deliver consistent, appropriate, accurate and complete and covered by the principles of building a mental health assessment and checking their validity according to the content by considering content validity. The results were calculated according to the formula. IOC values of all items were 0.90 , which was greater than 0.50 , indicated that the mental health assessment was consistent with the research objectives, and data could be collected. And there is the evaluation of the suitability of the mental health assessment with a 5-level estimation scale questionnaire. The results of the suitability assessment of the mental health power assessment were found that the suitability value was 4.77 , which is more than 3.50 .

4) Take the mental health evaluation form to try out on 30 second year nursing undergraduate students to find the power to classify each item and the confidence of the whole issue, it was found that the power to classify each item had a value of 0.20 and above, it was found that all questions had the power to classify each item at the applicable level, namely, the discriminant power from 0.36 - 0.92. As for the whole confidence of the mental health force assessment, it was found that the confidence value was 0.958 , indicating that all of the mental health assessments were satisfied that an acceptable value of 0.70 or more could be used in the study collecting data.

\subsection{Data Collection}

1) Make a letter requesting permission to conduct human research to Srimahasarakham Nursing College, Faculty of Nursing, Praboromarajhanok Institute of Thailand.

2) Make a letter requesting permission from Srimahasarakham Nursing College, Faculty of Nursing, Praboromarajhanok Institute to collect information.

3) Data collect by a mental health power assessment questionnaire form for 91 first year nursing undergraduate students, Srimahasarakham Nursing College, Faculty of Nursing, Praboromarajhanok Institute of Thailand.

4) It took 3 months to collect the data.

5) Analyze the data and presenting information.

\subsection{Research Statistics}

1) Basic statistics are frequency, percentage, mean and standard deviation.

2) The statistics used in the analysis for the tool quality were content validity, discriminant power of the questionnaire confidence value process.

3) The statistics used in hypothesis testing were spearman's correlation coefficient at the statistical significance .05.

\section{Results}

The study the level of mental health power and selected factors related to mental health power of nursing undergraduate students, Srimahasarakham Nursing College, Praboromarajhanok Institute of Thailand can be summarized as follows:

1) The study of mental health power level of nursing undergraduate students, Srimahasarakham Nursing College found that the general information of 91 first year nursing students found that most of them were 19 years old $(67.00 \%)$, the majority of them were female people $(96.70 \%)$. Number of siblings or children who are 1 and 2 of (42.90\%) resided mostly in Maha Sarakham (36.30\%), the average monthly income of about 3,001-5,000 baht $(52.70 \%)$.

Table 3. Results of mental health power analysis of first year nursing students $(n=91)$.

\begin{tabular}{|c|c|c|c|c|c|c|}
\hline \multirow[t]{2}{*}{ Mental health power } & \multicolumn{2}{|c|}{ Below the threshold } & \multicolumn{2}{|c|}{ Normal } & \multicolumn{2}{|c|}{ Above the threshold } \\
\hline & frequency & Percentage & Frequency & $\begin{array}{c}\text { Percentag } \\
\text { e }\end{array}$ & Frequency & Percentage \\
\hline Emotional stability (1-10) & 33 & 36.30 & 53 & 58.20 & 5 & 5.50 \\
\hline Morale (11-15) & 66 & 72.50 & 25 & 27.50 & - & - \\
\hline $\begin{array}{l}\text { Problem management } \\
(16-20)\end{array}$ & 23 & 25.30 & 68 & 74.70 & - & - \\
\hline $\begin{array}{c}\text { Total } \\
\text { (overall score of all aspects) }\end{array}$ & 31 & 34.10 & 60 & 65.90 & - & - \\
\hline
\end{tabular}


The highest overall mental health power of the first year nursing undergraduate students in each area was emotional stability in the normal number of $53(58.20 \%)$, the morale is below the threshold of $66(72.50 \%)$ and the management of problems was in the norm of $68(74.70 \%)$. The overall score of all aspects was in the normal range of $60(65.90 \%)$ while the overall mean of mental health was below the threshold $\left(\mathrm{x}^{-}=57.64\right)$. When considering the mental health aspects of each aspect, it was found that the emotional stability $\left(\mathrm{x}^{-}=29.98\right)$, morale $\left(\mathrm{x}^{-}=13.81\right)$ and problem management $\left(\mathrm{x}^{-}=14.84\right)$ were below all criteria.

Table 4. Mean score and standard deviation mental health power of nursing undergraduate students.

\begin{tabular}{lcccl}
\multicolumn{1}{c}{ Mental health power } & Full score & $\overline{\boldsymbol{x}}$ & S.D. & Assessment results \\
\hline Emotional stability & 30 & 28.98 & 3.37 & Below the threshold \\
Morale & 19 & 13.81 & 1.32 & Below the threshold \\
$\begin{array}{l}\text { Problem management } \quad \text { Total } \\
\quad 16\end{array}$ & 14.84 & 1.83 & Below the threshold \\
$\quad$ (overall score of all aspects) & $\mathbf{6 5}$ & $\mathbf{5 7 . 6 4}$ & $\mathbf{5 . 0 5}$ & Below the threshold
\end{tabular}

2) The effect of the selected factor correlated with the mental health power of nursing undergraduate students at Srimahasarakham Nursing College found that the factors that had a positive correlation with the mental health power of nursing undergraduate students the statistical significance level. 05 including: age correlated at a moderate level ( $\mathrm{r}$ $=.04)$, domiciled correlated a low $(\mathrm{r}=.01)$ and monthly income correlated at a moderate level $(\mathrm{r}=.03)$. The factors that did not correlate with the mental health power of nursing undergraduate students were gender $(r=.10)$ and the order of siblings or their children $(\mathrm{r}=.09)$.

Table 5. Spearman's correlation coefficient between age, gender, domicile, order of siblings or children with whom and monthly income and overall mental health vitality of nursing students $(n=91)$.

\begin{tabular}{|c|c|c|c|c|c|c|}
\hline Variable & 1 & 2 & 3 & 4 & 5 & 6 \\
\hline 1. Age & 1 & - & - & - & - & - \\
\hline 2. Gender & -.02 & 1 & - & - & - & - \\
\hline 3. Domicile & -.17 & .00 & 1 & - & - & - \\
\hline $\begin{array}{l}\text { 4. Order of siblings or } \\
\text { children with whom }\end{array}$ & .037 & -.06 & -.06 & 1 & - & - \\
\hline 5. Monthly income & .06 & -.16 & .15 & .15 & 1 & - \\
\hline 6. Mental health power & $.04 *$ & .10 & $.01 *$ & .09 & $.03 *$ & 1 \\
\hline
\end{tabular}

* Statistically significant .05

\section{Discussion}

The effect of selected factors correlated with mental health power of nursing undergraduate students. The researcher has the following points to discuss:

1) There was the effect of the mental health power level of nursing undergraduate students of Srimahasarakham Nursing College found that the overall mental health power of the first year nursing students in each area was the most, namely the emotional stability, in the normal range $(58.20 \%)$, morale is below the threshold $(72.50 \%)$ and dealing with problems in the normal range $(74.70 \%)$, overall score in all areas is normal $(65.90 \%)$. Whereas the mean overall mental health power was lower than the criterion. When considering the mental health power, found that emotional stability, morale, and problem management were below all criteria.

1.1) Emotional stability this is in line with the concept of the Department of Medical Services (2010) meaning that mental health is the condition of a person who can solve problems, adjust the mind to suit the society and environment according to reality. Mental health consists of emotional, mental and social happiness. This can affect our thoughts, feelings and actions. Mental health is also what helps us deal with stress, interactions and decision-making. And according to the concept of the Department of Mental Health, Office of Mental Health Development (2012) said that emotional endurance (strength) is the ability to regulate emotions, not to be sensitive, to tolerate under stressful situations without losing mental health. The people have emotional stability in any situation, they can stay stable. And get through that situation people who are emotionally unstable are more likely to have reactions, such as being unable to eat or sleep, be sad alone which can lead to physical and mental health problems which consistent with the study 
results of Kotchakorn Chayakul (2018) entitled the effect of the resilience quotient enhancement program among nursing students of Boromarajonani of Nursing College, Nakhonratchasima found that the overall mental health power of the sample in the pre-trial research was scored between 47 and $55(\mathrm{M}=53.36$, S.D $=2.33)$ with the mental health power of emotional stability between 24 and 27 (M -25.63, S.D = 0.92). However, after all 3 trials in the program, the overall mental health power of the research sample estimated between 53 and 69 points $(M=60.18$, S.D $=5.32)$ with the mental health power of emotional stability between 25 and $33(\mathrm{M}=28.81, \mathrm{~S} . \mathrm{D}=2.78)$. And Sarinya Polsingchan \& Komwat Rungruang (2018) studied entitled the factors related to resilience quotient of end stage renal disease (ESRD) patients receiving hemodialysis at Surin Hospital to analysis of mental health power levels of end-stage renal failure found that patients undergoing hemodialysis patients with chronic kidney disease most of them had a level of mental health power, including emotional stability, morale and problem management in the normal range. And Siriporn Buranakunkitkan et al., (2018) studied the relationships between protective factors and resilience among schizophrenia caregivers found that the mental health power of the schizophrenic caregivers overall and classified into the overall mental health power of schizophrenic caregivers at the normal level mean score $62.53(\mathrm{SD}=$ 10.85). Separately, each side consisted of normal emotional endurance. The average score was 30.67 ( $\mathrm{SD}=4.81$ ), morale was in normal condition have a mean score of $16.37(\mathrm{SD}=2.99)$. The problem management is at a normal level have an average score of $15.49(\mathrm{SD}=3.00)$.

1.2) Morale, which is based on the concept of Teppagone Pittayaiinune (2011), said that mental health or mental health is a happy life stable temper satisfied with their condition. It is able to adapt well to the environment and change, able to coexist with those around him happily and face problems properly. And according to the concept of Department of Mental Health, Office of Mental Health Development (2009) said that morale (strength) is a mind with determination, not giving up, having the power to overcome problems, obstacles, or break through to success. Encouragement is something that is especially important when there are problems or crises in life. Not fighting life, thinking only about sorrow or suffering, people who are not motivated will not fight, if sick or old age, worsening encouragement will make sick more which is consistent with the study results of Punvadee Somkittikanon, Phattarakorn Muksrinak \& Kulthida Seebuaban (2017) studied the relationships between resilience quotient and learning outcome of psychology courses of psychology students, Saint Louis College, found that mental health power of students in the field psychology and teaching models of each form of mental health power components of first to year four psychology students consisted of searching, emotional stability, encouragement and dealing with problems have overall mean and resistance at normal levels. The opinions towards the teaching model 1 and the 2 were the overall average and the resistance was at a high level. And Ammaret Netasit et al., (2012) studied the development of resilience quotient (RQ) support activities set for flooded communities: a case study at Gluy Pae Sub-district, Mueang Lampang District, Lampang Province. When comparing the mental health power before and after activities, found that the number of villagers had mental health lower than normal, $12.50 \%$ lower and $12.50 \%$ of the villagers with mental health were at normal level. And villagers have mental health power increased to $25.00 \%$ higher than normal, overall, villagers had mental health increased after $17.98 \%$ of activities. Problem management increased the most by $18.76 \%$, followed by encouragement, increased by $17.86 \%$. And emotional stability increased by $17.12 \%$, respectively. And Somdee Ananpatiwet, Vipa Pengsa-ium \& Chunpen Akrasthitanon (2011) studied a comparison study of resilience quotient (RQ) before and after mental health \& psychiatric nursing practicum among junior nursing students, St Theresa International College, found that all aspects of mental health power were emotional stability. Morale and problem management were normal, both before and after the practice. By mental health power, the emotional stability and morale of nursing students were changing in an increasing direction. After the practice was statistically significant at the .001 level. As for the mental health power in dealing with problems of nursing students, there was a change in direction. The increase after the practice was statistically significant at the .05 level.

1.3) Problem management which is based on the concept of Withun Saengsingkaew (2015), said that the mentally ill person is not just the person who does not have a mental fluctuation but also the person who can adjust the mental state to be suitable for the environment at the time of life. That is, the happiness of the heart has an abstract value. Which is based on the concept of Vatinee Sukmak (2013) said that the characteristics of people who are in good health and not in good health are those with poor mental health being able to experience events well in normal and irregular situations and can control their emotions. And who are opposed to those who adapt poorly, not knowing and not understanding themselves, do not know and do not understand others as well as being unable to face the problems and truths of life, making them unable to live in a normal society. A normal person, when subjected to severe traumatic conditions or events, creates a prolonged stress, the behavior may become abnormal and thus unable to carry out activities for a normal life. The changes lead to mental health problems, the problems are more severe depending on the cause and the duration of the trauma, factors that are important to mental health. Which is based on 
the concept of Department of Mental Health, Office of Mental Health Development (2012) said that problem management (fighting power) is an attempt to solve a problem by thinking of the reasons for solving the problem, finding out the root cause of the problem. Listen to other people's opinions find the best solution and evaluate whether the method works. If the problem is serious, seek advice from someone in the know or seek help from others. People who run away from problems are motionless, not eager to solve them, overcome obstacles or solve problems. Who do not know if there is a possibility or not this will cause the problem to be unresolved or may lead to additional problems. The mental health assessment helps you to know the overall self-efficacy of your mental health. It also helps them to know how well they are emotionally tolerant, encouraged and know how to deal with problems which is consistent with the study results of Sakda Khumkom (2018) studied the effects of group activities on the development of emotional and resilience quotients of the first year nursing students of Suranaree University of Technology found that the mean scores of the emotional intelligence and mental health of the students before and after participating in the experimental group and after the group activity between the experimental and control groups. When comparing the mean scores of emotional intelligence and mental health strength of the experimental group students before and after participating in group activities. It was found that the average score of emotional intelligence and mental health of students after participating in group activities had higher scores than before participating in group activities, statistically significant ( $\mathrm{p} .001$ ). And when comparing students' mean scores of emotional intelligence and mental health vitality after participating in group activities between experimental and control groups, found that the mean scores of the emotional intelligence of the experimental group were higher than the control group statistically significant (p. 01). There was the difference of mean score of the students' mental health power between the control group and the experimental group, statistically significant (p. 05). And Jansuda Jannoppacun \& Siriluck Suppapitiporn (2015) studied predictive factors for the resilience quotient of new nursing graduates on rotational duty at Chulalongkorn Hospital, found that the mental health power score of new graduates working in Chulalongkorn Hospital, overall majority is in the normal range $75.2 \%$. And in 3 sub-areas: emotional stability, morale, and problem management, likewise, most of the three trends were in the normal range, $74.0 \%, 83.4 \%$ and $85.5 \%$ respectively. In terms of dealing with problems, the score was as low as $98 \%$. And those with a high problem handling score were 4.7\%. And Thepthai Chotchay \& Phanomphon Miraket (2010) studied the factors associated with personnel's resilience quotient level in Sirindhorn College of Public Health Khon Kaen, found that most of the personnel had overall mental health power of $63.8 \%$, followed by $31.4 \%$ and $4.8 \%$ below the normal level, respectively. When considered individually, found that most of the emotional endurance (endurance) was $69.5 \%$ normal followed by those at the level above the norm and below the norm $21.9 \%$ and $86 \%$, respectively. Most of the morale (persistence) was at the normal level, $71.4 \%$, followed by a higher than normal level and below the norm by $23.8 \%$ and $4.8 \%$, respectively. In terms of dealing with problems (fighting), most of them were in the normal range $76.2 \%$, followed were at a higher than normal level and $19.0 \%$ and $4.8 \%$ higher than the norm, respectively, found that the duration of work and the disease was significantly associated with the mental health power level (p-value <0.05).

2) The study of the selected factor correlated with the mental health power of nursing undergraduate students at Srimahasarakham Nursing College found that the factors that had a positive correlation with the mental health power of nursing undergraduate students statistically significant at the .05 level.

2.1) The factor of age positively correlated with the mental health power of nursing undergraduate students is moderate $(\mathrm{r}=.04)$, which is based on the concept of Vatinee Sukmak (2013) mental health is an important factor for mental health. Mental health problem is a complex and complex mental state. In psychology, it is believed that mental health problems can be categorized into two groups and external personnel, which is based on the concept of Siriwan Serirat (1995) said that age is a factor in how people think and behave differently. Younger people tend to have liberal thoughts, upholding ideology and being more optimistic than older people, while older people tend to have a conservative mindset, adhere to careful practice pessimism than the younger, due to different life experiences. Which is consistent with Saowanit Noimongkon, Wilaipun Somboontanont \& Venus Leelahakul (2017) studied the selected factors related to resilience in family caregivers of older adults with dementia, found that relationship between caregiver age, caregiver income, length of service, cognitive impairment level of elderly with dementia, self-efficacy of caregivers and social support of caregivers and mental health power of elderly caregivers with dementia, found that the factors that positively correlated with the mental health power of the elderly caregivers with dementia were significantly at the .01 level, namely the age of the caregivers $(\mathrm{r}=.27, \mathrm{p}<.01)$, social support $(\mathrm{r}=.45, \mathrm{p}<.01)$. Factors that were positively correlated with the mental health vitality of the elderly caregivers with dementia significantly at levels .05, were cognitive impairment levels of the elderly with dementia $(r=.24, p<.05)$. Perceived self-performance of self-care careers and their receiving assistance when needed to rest $(r=.30, p<.05)$. Perception of self-efficacy of caregivers in response to chaotic behavior of the patient $(\mathrm{r}=.25, \mathrm{p}<.05)$. And self-efficacy of caregivers in their 
ability to control poor care thoughts $(\mathrm{r}=.22, \mathrm{p}<.05)$. The non-correlated factors of mental health power of elderly caregivers with dementia were: length of service provider $(r=.06, p>.05)$, and the income of the caretaker $(r=.28$, $\mathrm{p}>.05$ ). The age of caregivers was significantly positively related to mental health energy. In other words, the aged caregivers will result in a high level of mental health. This may be because the majority of the sample were in the middle age (36-59 years) $88.6 \%$. The middle adulthood is an experienced age, managing, coping with problems and adjusting, having coping decisions and self-care and patient skills. And Lerluk Mahiphun, Capt.Chanudda Nabkasorn \& Duangjai Vatanasin (2017) studied the factors related to spiritual well-being among caregivers of schizophrenic patients, found that age was significantly associated with the cognitive health of schizophrenic caregivers at level <.05 $(r=.200)$. Can be discussed as the majority of the caregivers of schizophrenic patients were between 41-60 years of age and were in the middle age according to the developmental stage. It is the age that wants to benefit society and future generations at the same time, with increasing age, a person has the opportunity to learn things from life experience. Increasing maturity and knowing what is good and what to do leads to good deeds for oneself, family, community and public persistent selfishness is what happiness, which is one element of cognitive well-being.

2.2) The factor of homeland was positively related to the mental health power of nursing undergraduate students at a low level $(\mathrm{r}=.01)$ which is based on the concept of Civilian SE Curity Organization (2015) said that the domicile is a residence where a natural person expresses his intention to be domiciled, the domicile of a person of the specific type prescribed by law. That place is the refuge for that person based on reality such a place is not necessarily a resident of the census, permanent residence, permanent residence or residence or regular work, but must not be temporary or short-term residence. Even though the census has been moved to this dormitory which is consistent with Rattanaphon Phanphot et al., (2016) studied the factors influencing mental health status among non-commissioned police officers, found that overall mental health had an average score of 1.57 (S.D. $=3.42$ ), indicating that the sample group was in good sanity, work stress is the most influential factor (Beta $=.221, \mathrm{p}<.05$ ). And family ties is the second influential variable (Beta $=-.202, \mathrm{p}<.05$ ). These two variables accounted for the variance in mental health conditions by $12.10 \%$. And the police's homeland variable could not predict the mental health status of the sample, due to migration within Thailand, a person can adapt to different environment.

2.3) The factor of monthly income was positively related to the mental health power of nursing undergraduate students is moderate $(r=.03)$ which is based on the concept of Siriwan Serirat (1995) said that socioeconomic status refers to a person's occupation, income and social status having a significant influence on the recipient's reaction to the messenger. Because each person has a culture of experience, different attitudes, values and goals certain factors related to each recipient, such as psychological and social factors that influence the reception of information. Which is consistent with Sarinya Polsingchan \& Komwat Rungruang (2018) studied the factors related to resilience quotient of end stage renal disease (ESRD) patients receiving hemodialysis at Surin Hospital, found that the power of mental health patients that chronic kidney disease, end stage receiving dialysis with artificial kidneys. Most have a level of mental health power in the normal range $(56.41 \%)$ and have a level of mental health higher than the norm, 11 people $(14.63 \%)$. Which is more female than male $(15.91 \%$ and $11.77 \%$, respectively). Mental health power is related to the status, education level and monthly income with statistical significance at the .05 level. In addition, mental health power is also associated with monthly income. More costly for end-stage renal failure patients on hemodialysis must have treatment including travel expenses for blood dialysis, medicine, treatment fees. Therefore, patients have adequate monthly income will make them self-sufficient. There is the potential for life live life and felt no burden to the family. And Tieantong Harabutra et al., (2019) studied the variables related to happiness among nursing students, Faculty of Nursing, Kasem Bundit University, found that $82.3 \%$ of nursing students were happy. Variables related to happiness of nursing students were age, self-worth, stress, mental health, family and friend relationships with statistical significance at the .05 level. The correlation coefficient (r) of 9 aspects were related to happiness. They were statistically significant at the .05 level in four areas: age (-.172), self-worth (.358), stress (-.386), mental health (350). There were 5 variables that were not related to happiness: family income (.027), student expenditure (-.120), cumulative GPA (.005), sleep duration (.099) and body mass index (.029).

2.4) The factors of gender $(\mathrm{r}=.10)$ did not correlate with the mental health power of nursing undergraduate students which is based on the concept of Department of Mental Health, Office of Mental Health Development (2009) explain that when people are emotional and psychological suffering, sorrow, disappointment, pain is severe, a lot of circumstances. Over time, you will be able to adjust and regain happiness naturally. This will be faster or slower depending on the potential for adaptation and recovery that vary according to each person. Some parts recovered better than in the face of new crises, but not as good as the original. And Siriwan Serirat (1995) said that gender refers to gender that is inherently defined and is a term for the biological state. Immutable it determines the roles and duties of female and male play a role have different. Gender refers to femininity, masculinity that comes from a sense of 
personal and legal status. It is something culturally cultivated to play a female role or a male role. Therefore, the gender is determined by this society. It may change as circumstances and conditions of the male in the next period of time. The characteristics of each gender that appear it's not something that happens naturally. It is created through a process of socialization as a part of social identity. Therefore, gender defines the identity, skills, and relationships of people of each gender. Gender differences causing individuals to have different communication behaviors that is females are more likely. There is a greater demand to send and receive information than males. While males do not have the sole need to send and receive messages. But there is a need to build a good relationship through receiving and sending that information. Additionally, females and males were differ greatly in their thinking, values and attitudes. This is because culture and society different roles and activities of the two sexes are defined which is consistent with of Chutrudee Parayat, Waree Kangchai \& Sirilak Somanusorn (2016) studied predictive factors of resilience among elderly, found that half of the subjects had a high level of mental health and a moderate mean of mental energy $(\mathrm{M}=144.29, \mathrm{SD}=14.98)$. Social support and the health perception were able to jointly predict the mental health vitality of $30.9 \%$ of the elderly at a statistically significant level of .01 . The gender factor income sufficiency and morale cannot predict the mental health power of the elderly. Gender factors cannot predict the mental health vitality of the elderly. It may be because mental health power is a person's ability to adapt to various difficult situations. Where mental health power remain or increase, when a person is able to successfully adjust to a difficult situation. And Tammakran N, Kanchanatawan B. (2014) studied the resilience quotient and related factors of papers industrial employees in Nakhon Pathom Province, found that 6 factors positively related to mental health vitality were male. And Pakasorn Uraiwan. (2011) studied factors related to the mental health power of the people in Surat Thani province, found that gender has no relationship with mental health power.

2.5) The factor of siblings or children $(r=.09)$ did not correlate with mental health power of nursing undergraduate students which is based on the concept of Sawitri Thayansin (2011) said having a good relationship with one another within the family is a factor that encourages the family to have love and bond, have understanding forgive one another and support one another when faced with obstacles and create a warm family. But weak relationships can result in a lack of warmth in families and higher rates of divorce. This fact is happening to Thai society from the warm family index, which is considered in need of improvement, there is also a worse direction which is consistent with Phawida Paninakul, Pornpat Hengudomsub \& Duangjai Vatanasin (2019) studied the influencing of psychosocial factors on happiness among community-dwelling older adults, found that the samples have remained high $(M=4.72, S D=18)$, the optimism and vitality, mental health can predict happiness of the elderly was $18.6 \%$. The most influential factor is optimism and followed by mental health power for the recognition of their own abilities and family relationships can not predict happiness, showed that most of the elderly had a mostly good perceived level of their abilities. As with the family relationships studied in this research, found that the happiness of the elderly cannot be predicted. This may be because most of the older people in this study were still living with their families. And social patterns in the study area, although, there are more industrial sites. And Nathiparat Jitabut, Duangjai Vatanasin, Pornpat Hengudomsub (2018) studied the psychosocial factors associated with well-being among persons with type 2 diabetes, found that social support was moderately positively associated with well-being in life. Showed that a sample with moderate social support might predict a relatively high tendency of their well-being which can be described as people with type 2 diabetes with high social support have a positive awareness of help from individuals or groups in society and close family members. Which has support for both intimacy being part of society to be encouraged to develop feelings and self-worth, including the presence of a support person social support is important to help people with type 2 diabetes stay motivated, frustrated, not stressed. And Wannarin Wuttiprom, Jularat Wattana \& Choosak Ueangchokchai (2019) studied factors influencing voluntary behaviors: case study of Thai Holistic Health Foundation, found that social factors include the family support network and the presence of a volunteer model was moderately associated with statistical significance of the volunteer behavior at the .05 level. With support from family, there was a moderate correlation with the volunteer behavior of the Thai Health Foundation with statistical significance at the .01 level $(\mathrm{r}=$ 0.428). And it was the social factor that was most related to volunteer behavior.

\section{Conclusion}

The results showed that the mean of overall mental health power was lower than the criteria $\left(\mathrm{x}^{-}=57.64\right)$. When considering mental health power on each aspect, it was found that emotional stability $\mathrm{x}^{-}=28.98$, encouragement $\mathrm{x}^{-}=$ 13.81 and problem management $\mathrm{x}^{-}=14.84$ which is below the threshold level on all aspects. And factors that had a positive correlation with the mental health power of nursing undergraduate students statistical significance $(\mathrm{p}<.05)$. There was also a moderate correlation $(\mathrm{r}=.04)$ were associated homeland low level $(\mathrm{r}=.01)$ and monthly income had a moderate relationship $(\mathrm{r}=.03)$. The factors that did not relate with the mental health power of nursing undergraduate students were gender $(\mathrm{r}=.10)$ and the order of siblings or their children $(\mathrm{r}=.09)$. 


\section{Acknowledgements}

This research was successfully completed thanks to the great kindness and help from the Srimahasarakham Nursing College, Praboromarajhanok Institute, Maha Sarakham, Thailand and this research project is financially supported by Mahasarakham University and Center of Environmental Education Research and Training, Faculty of Environment and Resource Studies, Mahasarakham University.

\section{References}

Ammaret Netasit et al. (2012). Development of Resilience Quotient (RQ) Support Activities Set for Flooded Communities: a Case Study at Gluy Pae Sub-district, Mueang Lampang District, Lampang Province. Journal of Education Studies, 44(3), July-September, 238-250.

Areewan Klunklin et al. (2008). Readiness of nursing students for problem-based learning. Nursing Journal, 35(2), April-June, 1-9.

Atsawini Manakankham et al. (2004). Because of the stress factors and stressors of nursing students to practice on the wards. Chiang Mai, Faculty of Nursing Chiang Mai University.

Chutrudee Parayat, Waree Kangchai \& Sirilak Somanusorn. (2016). Predictive Factors of Resilience among Elderly. The Journal of Faculty of Nursing Burapha University, 24(2), April-June, 97-106.

Civilian SE Curity Organization. (2015). Domicile means. [Online]. From: https://www.secnia.go.th. [Retrieved 28 April 2019].

Department of Medical Services. (2010). Practices for the prevention and treatment of obesity. Bangkok, Institute of Medical Research and Technology Assessment.

Department of Mental Health, Office of Mental Health Development. (2009). Change bad to good, Mental health power. Bangkok, Dina Du Publishing.

Department of Mental Health, Office of Mental Health Development. (2012). Training Manual Strengthening mental health for the local media. Nonthaburi, Sankit Publishing.

Jansuda Jannoppacun \& Siriluck Suppapitiporn. (2015). Predictive Factors for the Resilience Quotient of New Nursing Graduates on Rotational Duty at Chulalongkorn Hospita. Thai Journal of Nursing Council, 30(2), April-June, 113-126.

Kotchakorn Chayakul. (2018). Effect of the Resilience Quotient Enhancement Program among NursingStudents of Boromarajonani Collegeof Nursing, Nakhonratchasima. The Journal of Baromarajonani College of Nusing, Nakhonratchasima, 24(2), July-December, 96-107.

Lerluk Mahiphun, Capt.Chanudda Nabkasorn \& Duangjai Vatanasin. (2017). Factors Related to Spiritual Well-Being among Caregivers of Schizophrenic Patients. Journal of Public Health Nursing, 3(2), May-August, 29-42.

Nathiparat Jitabut, Duangjai Vatanasin \& Pornpat Hengudomsub. (2018). Psychosocial Factors Associated With Well-Being Among Persons With Type 2 Diabetes. The Journal of Psychiatric Nursing and Mental Health, 32(1), January-April, 102-118.

Pakasorn Uraiwan. (2011). Factors related to the mental health power of the people in Surat Thani province. Surat Thani, Boromarajonani College of Nursing.

Phawida Paninakul, Pornpat Hengudomsub \& Duangjai Vatanasin. (2019). Influencing of Psychosocial Factors on Happiness among Community-Dwelling Older Adults. The Journal of Faculty of NursingBurapha University, 27(2), April-June, 40-48.

Punvadee Somkittikanon, Phattarakorn Muksrinak \& Kulthida Seebuaban. (2017). Relationships between Resilience Quotient and Learning Outcome of Psychology Courses of Psychology Students, Saint Louis College. Journal of The Royal Thai Army Nurses, 18(3), September-December, 160-169.

Rattanaphon Phanphot et al. (2016). Factors Influencing Mental Health Status Among Non-commissioned Police Officers. Christian University Journal, 22(4), October-December, 460-470.

Sakda Khumkom. (2018). Effects of Group Activities on the Development of Emotional and Resilience Quotients of the First Year Nursing Students of Suranaree University of Technology. Journal of the Veridian E-Journal, Silpakorn University, 11(2), May-August, 2767-2780. 
Saowanit Noimongkon, Wilaipun Somboontanont \& Venus Leelahakul. (2017). Selected Factors Related to Resilience in Family Caregivers of Older Adults with Dementia. Nursing Journal of the Ministry of Public Health, 27(1), January-April, 85-98.

Sarinya Polsingchan \& Komwat Rungruang. (2018). Factors Related to Resilience Quotient of End Stage Renal Disease (ESRD) Patients Receiving Hemodialysis at Surin Hospital. Boromarajonani College of Nursing, Uttaradit Journal, 10(1), January-June, 129-141. https://doi.org/10.2174/1874350101912010141

Sawitri Thayansin. (2011). Family ties. Mahidol University, National Institute for Child and Family Development.

Saymai Tumwichit et al. (2009). Stress Assessment, Stress Factors and Coping Patterns during Clinical Nursing Practicum Among Junior Nursing Students in College of Nursing of Christian University if Thailand. Christian University Journal, 15(2), May-August, 115-129.

Siriporn Buranakunkitkan et al. (2018). Relationships between Protective Factors and Resilience among Schizophrenia Caregivers. Nursing Journal of the Ministry of Public Health, 28(1), January-April, 24-35.

Siriwan Serirat. (1995). Consumer behavior. Bangkok, Thai Watanapanich.

Somdee Ananpatiwet, Vipa Pengsa-ium \& Chunpen Akrasthitanon. (2011). A Comparison Study of Resilience Quotient (RQ) Before and After Mental Health \& Psychiatric Nursing Practicum Among Junior Nursing Students, St Theresa International College. Journal of nursing and education, 4(1), January-April, 38-51.

Tammakran, N., \& Kanchanatawan, B. (2014). Resilience quotient and related factors of papers industrial employees in Nakhon Pathom Province. Chula Med J, 58(4), Jul-Aug, 443-455.

Teppagone Pittayaiinune. (2011). Mental health in daily life. Songkhla, Banlue Printing House.

Thepthai Chotchay \& Phanomphon Miraket. (2010). Factors associated with personnel's Resilience Quotient level in Sirindhorn College of Public Health Khon Kaen. Sustainable Rural Development Academic Conference 2012 "Local Communities Foundations for the development of the ASEAN Economic Community", 16-19, February 2012, 306-312.

Tieantong Harabutra et al. (2019). Variables Related to Happiness among Nursing Students, Faculty of Nursing, Kasem Bundit University. Kasem Bundit Journal, 20(2), July-December, 68-80.

Vatinee Sukmak. (2013). Mental health and psychosocial nursing. Maha Sarakham, Mahasarakham University.

Wannarin Wuttiprom, Jularat Wattana \& Choosak Ueangchokchai. (2019). Factors Inflfluencing Voluntary Behaviors: Case Study of Thai Holistic Health Foundation. Integrated Social Science Journal, Faculty of Social Sciences and Humanities, Mahidol University, 6(1), January-June, 78-99.

Withun Saengsingkaew. (2015). The definition of mental health. [Online]. From: http://sukanya1996oom. blogspot.com/. [Retrieved 26 April 2020].

\section{Copyrights}

Copyright for this article is retained by the author(s), with first publication rights granted to the journal.

This is an open-access article distributed under the terms and conditions of the Creative Commons Attribution license (http://creativecommons.org/licenses/by/4.0/). 